\title{
Response to: Hypoglossal Nerve Unjury after Cervical Spine Surgery
}

\author{
Tatsuya Yasuda, Daisuke Togawa, Tomohiko Hasegawa, Yu Yamato, \\ Sho Kobayashi, Hideyuki Arima, Yukihiro Matsuyama \\ Department of Orthopaedic Surgery, Hamamatsu University School of Medicine, Hamamatsu, Japan
}

We are extremely grateful for your interest in our manuscript. The report by Saunders et al. was very helpful. As you indicated, there are reports about hypoglossal nerve palsy (HNP) after soft tissue surgery of the neck. Although there are only three reports [1-3] of HNP after cervical spine surgery, more cases might exist. Therefore, we must pay attention to tongue movement after anterior cervical spine surgery.

We think that HNP after anterior cervical spine surgery is caused by excessive intraoperative retraction. In our case, only osteophyte resection was performed. Therefore, the duration of operation time was markedly shorter than the other two cases $[2,3]$. The duration of pressure time is related to the extent of nerve damage. If the surgical time was longer, permanent HNP could have occurred in our case as with other two cases. We think that intermittent release of retraction is important to avoid hypoglossal nerve damage.

We greatly appreciate for the opportunity to discuss the issues raised, and thank you for your interest in our study.

\section{Conflict of Interest}

No potential conflict of interest relevant to this article was reported.

\section{References}

1. Yasuda T, Togawa D, Hasegawa T, et al. Hypoglossal nerve palsy as a complication of an anterior approach for cervical spine surgery. Asian Spine J 2015;9:2958.

2. Sengupta DK, Grevitt MP, Mehdian SM. Hypoglossal nerve injury as a complication of anterior surgery to the upper cervical spine. Eur Spine J 1999;8:78-80.

3. Saunders RL, Bernini PM, Shirreffs TG Jr, Reeves AG. Central corpectomy for cervical spondylotic myelopathy: a consecutive series with long-term followup evaluation. J Neurosurg 1991;74:163-70. 